\title{
Fuzzy Data Envelopment Analysis with SBM using $\alpha$-level Fuzzy Approach
}

\author{
Qaiser Farooq Dar \\ Division of International Trade \\ Incheon National University (INU), South Korea \\ qaiserdea@gmail.com
}

\author{
Ahn Young Hyo \\ Division of International Trade \\ Incheon National University (INU), South Korea \\ yhahn@inu.ac.kr \\ Gulbadian Farooq Dar \\ Department of Statistics, \\ Ramanujan School of Mathematical Sciencem, Pondicherry University, India \\ gulbadinstst.pu@gmail.com
}

Shariq Ahmad Bhat

Department of Commerce

Islamic College of Science and Commerce Srinagar-India

bhatshariq01@gmail.com

Arif Muhammad Tali

Department of Statistics

Amar Singh College, Srinagar Srinagar-India

arif9dea@gmail.com

Yasir Hamid Bhat

Department of Computer Science and Engineering

Islamic University of Science \& Technology,

Kashmir-India

bhatyasirhamid@pec.edu

\begin{abstract}
In this paper, a generalized ratio-type estimator based on ranked set sampling (RSS) is proposed for The applications of fuzzy analysis in data-oriented techniques are the challenging aspect in the field of applied operational research. The use of fuzzy set theoretic measure is explored here in the context of data envelopment analysis (DEA) where we are utilizing the fuzzy $\alpha$-level approach in the three types of efficiency models. Namely, BCC models, SBM model and supper efficiency model in DEA. It was observed from the result that the fuzzy SBM model has good discrimination power over fuzzy BCC. On the other side, both the models fuzzy BCC and fuzzy SBM are not able to make the genuine ranking which is acceptable for all. So this weakness is overcome with the help of fuzzy super SBM model and all three models are applied to illustrate the types of decisions and solutions that are achievable when the data are vague and prior information is in imprecise. In this paper, we are considering that our inputs and outputs are not known with absolute precision in DEA and here, we using Fuzzy-DEA models based on an $\alpha$-level fuzzy approach to assessing fuzzy data.
\end{abstract}

Keywords: Fuzzy Set, Linear Parametrical Programming, Data Envelopment Analysis, Vague, Fuzzy Equalities, and Inequalities. 


\section{Introduction}

Since DEA was proposed in 1978 and after that it has been got comprehensive attention in both theories as well as in application. DEA becomes an important analysis tool and research way in management science, operational research, system engineering, decision analysis, and economics. Performance analysis has become a vital part of the management practices in the banking industry. There are numerous applications using DEA models to estimate efficiency in banking, and most of them assume that inputs and outputs are known with absolute precision. The different modification was in the mathematical approaches of DEA, namely mixed orientation approach of DEA was given Qaiser et al. (2016). Two-stage production processes with double frontier were given by Arif et al. (2017). DEA as decision support system was given by Qaiser et al. (2017). But it is not always possible that our input and output data are known with absolute precision. DEA is based on the production process and the data of production processes cannot be precisely measured always since the uncertain theory has played an important role in the inputs and outputs. The fuzzy analysis is helpful for handling the different type of data, namely uncertainty data, interval data; identify the missing variable and high-frequency data. A possible path to handle input/output uncertainty in DEA relies on the use of probability distributions to model their inherent randomness. These distributions are subsequently employed in stochastic DEA models. However, these probability distributions require being somewhat estimable a priori or a posteriori, limiting the use of stochastic DEA models in cases where the event is unique or deterministic. Alternatively, however, uncertainty in input/output may be related to imprecision or vagueness, rather than to randomness. This being the case imprecision or vagueness in input/output values can be expressed by membership functions within the ambit of fuzzy logic.

The $\alpha$-level approach is possibly the most popular, given the numerous papers produced using its variations, despite the fact that their models are not computationally efficient. This is so because $\alpha$-level models demand more linear programs to be solved for each $\alpha$ value (Soleimani-damaneh, Abbasbandy et al., and Jahanshahlooet al., 2006) within the $\alpha$-level approach, the FDEA model is first converted into a pair of parametric programs so that the lower and upper bounds of the efficiency scores can be computed next for a given value of $\alpha$ in Emrouznejad and Tavana (2014). The rationale behind the selection of then $\alpha$-level approach in this study is related to a number of aspects. First, when using this approach, fuzzy inputs and outputs may be expressed as crisp numbers representing the limiting bounds of the intervals for different $\alpha$-levels in Chen et al. (2013), thus allowing the uncertainty of the data collected from Mozambican banks to be easily modelled as triangular fuzzy numbers. Second, in the situation of various $\alpha$ levels for the inputs and the outputs, Fuzzy DES may be translated into traditional DEA (crisp) models in light of the extension principle, thus making solving their respective linear programs simpler (Yager, 1981; Zadeh, 1965a; Zimmerman, 1976). Third, owing to the input and output data being fuzzy numbers, the efficiency scores are also fuzzy numbers in Puri and Yadav (2013). Moreover, as long as the efficiency values considered here are the upper and lower "crisp" bounds computed for various $\alpha$ levels, the membership functions for the true fuzzy efficiency cannot be reconstructed, which has a number of implications on how fuzzy efficiencies should be ranked in Chen et al.( 2013); Puri and Yadav (2013); Hsiao et al. (2011). These bounds, however, can be treated as crisp values and incorporated into statistical modelling as efficiency scores subjected to certain fixed 
effects or treatments in order to properly assess the impact of different contextual variables.

\section{DEA with Fuzzy Sets}

The two fundamental DEA models, CCR (Charnes Cooper Rhodes DEA-mode) and BCC (Banker Charnes Cooper DEA-model) are based on the assumption of know, numerical, and fixed value of inputs and outputs. But this type of input-output data are not always possible, sometimes we are observing that our observed input-output data are imprecise or vague. In such situations, the traditional DEA models fail to get any information from such type of data. So, in order to overcome from such type of difficulties, we are making the use of fuzzy theory. Sengupta (1992) was first introducing a fuzzy mathematical programming approach into which fuzziness was incorporated into DEA methodology.

Let us assume the $n-D M U s$ assessing the number of $m$ different inputs to produce $s$ different outputs. Suppose that $\tilde{x}_{i j} ;(i=1,2,3, \ldots, m)$ and $\tilde{y}_{r j} ;(r=1,2,3, \ldots, s)$ are respective fuzzy inputs and outputs of $D M U_{j} ;(j=1,2,3, \ldots n)$. The multiplier and envelopment form fuzzy CCR-model with input-oriented version can be formulated mathematically as:

Multiplier CCR-model (input-oriented)

$$
\operatorname{Max} \theta_{k}=\sum_{r=1}^{s} \mu_{r} \tilde{y}_{r k}
$$

Sub to

$$
\begin{aligned}
& \sum_{i=1}^{m} v_{i} \tilde{x}_{i k}=1 \\
& \sum_{r=1}^{s} \mu_{r} \tilde{y}_{r j}-\sum_{i=1}^{m} v_{i} \tilde{x}_{i j} \leq 0 ; \forall(j=1,2,3, \ldots, n) \\
& \mu_{r}, v_{i} \geq 0 ;(i=1,2,3, \ldots m \text { and } r=1,2,3, \ldots, s)
\end{aligned}
$$

Where $" \approx$ "denotes the fuzziness of input and outputs.

The model (2.1) is an input-oriented fuzzy CCR model in multiplier form. Envelopment form of the above model is more feasible to solve, which can convert by making the use of duality theory. Thus envelopment form of model (2.1) is as:

$\operatorname{Min} \theta_{k}$

Sub to

$$
\begin{array}{ll}
\sum_{j=1}^{n} \lambda_{j} \tilde{x}_{i j} \leq \theta_{k} \tilde{x}_{k j} & \forall i=1,2,3, \ldots, n \\
\sum_{j=1}^{n} \lambda_{j} \tilde{y}_{r j} \geq \tilde{y}_{r k} & \forall r=1,2,3, \ldots, s \\
\lambda_{j} \geq 0 & \forall j=1,2,3, \ldots, n .
\end{array}
$$

Where $\theta_{k}$ is an efficiency value of $k^{\text {th }}-D M U$. The model (2.2) is envelopment form of fuzzy CCR and can be solved by using the fuzzy linear programming and assumed in case of constant returns to scale production processes only. If the convexity constraint is 
adjoined to model (2.1), then the model becomes the fuzzy BCC model and mathematically formulation as:

$\operatorname{Min} \theta_{k}$

Sub to

$$
\begin{aligned}
& \sum_{j=1}^{n} \lambda_{j} \tilde{x}_{i j} \leq \theta_{k} \tilde{x}_{k j} \forall i=1,2,3, \ldots, n \\
& \sum_{j=1}^{n} \lambda_{j} \tilde{y}_{r j} \geq \tilde{y}_{r k} \quad \forall r=1,2,3, \ldots, s \\
& \sum_{j=1}^{n} \lambda_{j}=1 \quad \forall \lambda_{j} \geq 0 ; j=1,2,3, \ldots n .
\end{aligned}
$$

The above model is the envelopment form of fuzzy BCC model and standard form of model (2.3) is given as:

$\operatorname{Min} \theta_{k}$

Sub to

$$
\begin{aligned}
& \sum_{j=1}^{n} \lambda_{j} \tilde{x}_{i j}+s_{i}^{-}=\theta_{k} \tilde{x}_{k j} \forall i=1,2,3, \ldots, n \\
& \sum_{j=1}^{n} \lambda_{j} \tilde{y}_{r j}-s_{r}^{+}=\tilde{y}_{r k} \quad \forall r=1,2,3, \ldots, s \\
& \sum_{j=1}^{n} \lambda_{j}=1 \forall \lambda_{j} \geq 0 ; j=1,2,3, \ldots n . \\
& s_{i}^{-} \geq 0 \text { and } s_{r}^{+} \geq 0 ; \forall i, r
\end{aligned}
$$

Where $s_{i}^{-}$and $s_{r}^{+}$are the input and output slacks of $j^{\text {th }}-D M U_{s}$. If $\theta_{k}=1$ and all slacks are zero then the $D M U_{k}$ is said to be efficient but if one of the slack is non-zero, then $D M U_{k}$ under evaluation is weakly efficient (i.e., you can improve the efficiency of $D M U_{k}$ by reduce the current level of input or expend the outputs) and if $\theta_{k} \neq 1$ then $D M U_{k}$ is said to be inefficient. We can solve the above model into two phases, in phaseI, we are estimating the feasible optimal solution of fuzzy BCC-model by using fuzzy linear programming approaches after that we use the optimal value $\theta_{k}^{*}$ in order to calculate the values of the slack. Phase II of fuzzy BCC-model is given below:

$$
\operatorname{Min}\left(\sum_{i=1}^{m} s_{i}^{-}+\sum_{r=1}^{s} s_{r}^{+}\right)
$$

Sub to

$$
\begin{gathered}
\sum_{j=1}^{n} \lambda_{j} \tilde{x}_{i j}+s_{i}^{-}=\theta_{k} \tilde{x}_{k j} \quad \forall i=1,2,3, \ldots, n \\
\sum_{j=1}^{n} \lambda_{j} \tilde{y}_{r j}-s_{r}^{+}=\tilde{y}_{r k} \quad \forall r=1,2,3, \ldots, s
\end{gathered}
$$




$$
\begin{aligned}
& \sum_{j=1}^{n} \lambda_{j}=1 \forall \lambda_{j} \geq 0 ; j=1,2,3, \ldots n . \\
& s_{i}^{-} \geq 0 \text { and } s_{r}^{+} \geq 0 ; \forall i, r
\end{aligned}
$$

Thus the model (2.4) and model (2.5) can represent a two-phase DEA process involved input-orientation in given below:

$\operatorname{Min} \theta_{k}-\varepsilon\left(\sum_{i=1}^{n} s_{i}^{-}+\sum_{r=1}^{s} s_{r}^{+}\right)$

Sub to

$$
\begin{aligned}
& \sum_{j=1}^{n} \lambda_{j} \tilde{x}_{i j}+s_{i}^{-}=\theta_{k} \tilde{x}_{k j} \forall i=1,2,3, \ldots, n \\
& \sum_{j=1}^{n} \lambda_{j} \tilde{y}_{r j}-s_{r}^{+}=\tilde{y}_{r k} \quad \forall r=1,2,3, \ldots, s \\
& \sum_{j=1}^{n} \lambda_{j}=1 \quad \forall \lambda_{j} \geq 0 ; j=1,2,3, \ldots n . \\
& s_{i}^{-} \geq 0 \text { and } s_{r}^{+} \geq 0 ; \forall i, r
\end{aligned}
$$

\section{Fuzzy Approaches in DEA}

The application of fuzzy set theory in DEA categorized into four approaches available in the literature which are discussed under as:

\subsection{Tolerance approach}

The Tolerance approach was one of the first fuzzy approaches in DEA and that was introduced by Sengupta (1992) later the same approach was improved by Kahraman and Tolga (1998). The main idea in this approach to incorporate with uncertainty input and output data in DEA models by defining the tolerance levels on set if constraints violations. This approach does not treat fuzzy coefficients directly but it is fuzzified the inequality or equality signs. Although in most production processes fuzziness is present both in terms of not meeting specific objectives and in terms of the imprecision of the data, the tolerance approach provides flexibility by relaxing the DEA relationships while the input and output coefficients are treated as crisp.

\subsection{Fuzzy ranking approach}

The fuzzy ranking approach is another and popular technique in fuzzy DEA was initially developed by Guo and Tanaka (2001). In this approach, the main idea is to estimate the fuzzy efficiency scores of the DMUs by using fuzzy linear programming which requires ranking the fuzzy set. Besides this, the approach is based on the fuzzy DEA models in which fuzzy constraints involves fuzzy equalities and fuzzy inequalities and converted into crisp constraints by predefining and possibility level by comparison rule of fuzzy numbers. 


\subsection{Possibility approach}

The possibility approach is based on the fundamental principle of the possibility theory was imitated by Zadah (1977) and it was related to the theory of fuzzy sets by defining the concept of a possibility distribution as a fuzzy restriction which acts as an elastic constraint on the values that may be assigned to a variable. More specifically, if $F$ is a fuzzy subset of a universe of discourse $U=\{u\}$ which is characterized by its membership function $\mu_{F}$, then a proposition of the form " $X$ is $F$ ", where $X$ is variable taking value in $U$, induces a possibility distribution $\prod_{X}$ which equates the possibility of $X$ taking the value $u$ to $\mu_{F}(u)$ the compatibility of $\mathrm{U}$ with $\mathrm{F}$. in this $\mathrm{X}$ becomes a fuzzy variable which is associated with a probability distribution see (Zadah 1977).

The proposed possibility CCR model was developed by Lertworasirikul et al. (2003) where they applied the concept of chance-constrained programming (CCP) and the possibility of fuzzy events are represented by the following:

$\operatorname{Max} \theta_{k}=\bar{f}$

Sub to

$$
\begin{aligned}
& \left(\sum_{r=1}^{s} u_{r} \tilde{y}_{r k}\right)_{\beta}^{U} \geq \bar{f} \forall r=1,2,3, \ldots, s \\
& \left.\begin{array}{l}
\left(\sum_{i=1}^{m} v_{i} \tilde{x}_{i k}\right)_{\alpha_{0}}^{U} \geq 1 \\
\left(\sum \lambda_{i} \tilde{x}_{i k}\right)_{\alpha_{0}}^{L} \leq 1
\end{array}\right\} \forall i=1,2,3, \ldots, m \\
& \left(\sum_{r=1}^{s} u_{r} \tilde{y}_{r j}-\sum_{i=1}^{m} v_{i} \tilde{x}_{i j}\right)_{\alpha}^{L} \leq 0 \forall j=1,2,3, \ldots, n . \\
& u_{r}, v_{i} \geq 0, \forall r, i .
\end{aligned}
$$

Where $\beta \in[0,1], \alpha \in[0,1]$ and $\alpha_{0} \in[0,1]$ are predetermined admissible levels of possibility. The envelopment from of the model (3.1) after using the CC-transformation and then use of duality in the above model which required a form of fuzzy CRR is as:

$\operatorname{Max} \theta_{k}$

Sub to

$$
\begin{aligned}
& \left(\sum_{j=1}^{n} \lambda_{j} \tilde{x}_{i j}-\theta_{k} \tilde{x}_{i k}\right)_{\bar{\alpha}_{1}}^{U} \leq 0 ; \forall i=1,2,3, \ldots, m \\
& \left(\sum_{j=1}^{n} \lambda_{j} \tilde{y}_{r k}-\tilde{y}_{r p}\right)_{\bar{\alpha}_{2}}^{U} \geq 0 ; \forall r=1,2,3, \ldots, s \\
& \lambda_{j} \geq 0 ; \forall j=1,2,3, \ldots, n .
\end{aligned}
$$

The extension of the model (3.2) was in Lertworasirikul et al. (2003) in case of VRS case for developing fuzzy $\mathrm{BCC}$ which as: 
$\operatorname{Max} \theta_{k}$

Sub to

$$
\begin{aligned}
& \left(\sum_{j=1}^{n} \lambda_{j} \tilde{x}_{i j}-\theta_{k} \tilde{x}_{i k}\right)_{\bar{\alpha}_{1}}^{U} \leq 0 ; \forall i=1,2,3, \ldots, m \\
& \left(\sum_{j=1}^{n} \lambda_{j} \tilde{y}_{r k}-\tilde{y}_{r p}\right)_{\bar{\alpha}_{2}}^{U} \geq 0 ; \forall r=1,2,3, \ldots, s \\
& \left(\sum_{j=1}^{n} \lambda_{j}\right)=1 ; \forall \lambda_{j} \geq 0 ;(j=1,2,3, \ldots, n .)
\end{aligned}
$$

Where $\bar{\alpha}_{1} \in[0,1]$ and $\bar{\alpha}_{2} \in[0,1]$ are predetermined admissible levels of possibility.

\section{4. $\quad \alpha$-Level Approach}

The $\alpha$-level approach is the most used method in fuzzy DEA. This is evident by the large number published reported work of FDEA based on $\alpha$-level approach. The mathematical idea in this approach is to convert the FDEA model into a pair of parametric programming in order to find the lower and upper bounds of the $\alpha$-level membership functions of the efficiency score. Girod (1992) used the approach proposed by Carlsson and Korhonen (1986) to formulate the fuzzy BCC and free disposal hull (FDH) models which were radial measures of efficiency. In this model, the inputs could fluctuate between risk-free (upper) and impossible (lower) bounds and the outputs could fluctuate between risk-free (lower) and impossible (upper) bounds. The method was approximately the membership function of the fuzzy efficiency measures by applying the $\alpha$-level approach. Then the extension of the same approach was done by Zadeh (1976) and Zimmermenn (1996) and they transformed the fuzzy DEA model to a pair of parametric mathematical programs and used the ranking fuzzy numbers methods proposed by Chen and Klein (1997) for estimating the efficiency measures of DMUs. The optimal solution of the fuzzy BCC model (7.5) can be estimated by using a twolevel mathematical model. The two levels are using to calculate the lower and upper bounds of the fuzzy DEA model and efficiency scores for a specific $\alpha$-level as follow:

$$
\left(W_{k}\right)_{\alpha}^{L}=\left[\begin{array}{c}
\min \\
\left(x_{i j}\right)_{\alpha}^{L} \leq x_{i j} \leq\left(x_{i j}\right)_{\alpha}^{U} \\
\left(y_{r j}\right)_{\alpha}^{L} \leq y_{r j} \leq\left(y_{r j}\right)_{\alpha}^{U} \\
\forall i, j, r
\end{array}\right]\left\{\begin{array}{c}
\bar{w}_{k}=\max \sum_{r=1}^{s} u_{r} y_{r k}+u_{0} \\
\text { Sub to } \\
\sum_{i=1}^{m} v_{i} x_{i k}=1 \\
\sum_{r=1}^{s} u_{r} y_{r k}-\sum_{i=1}^{m} v_{i} x_{i j}+u_{0} \leq 0 ; \forall j .
\end{array}\right.
$$

Similarly, upper bounds of fuzzy DEA model and efficiency scores for a specific $\alpha$-level as follow: 


$$
\left(W_{k}\right)_{\alpha}^{U}=\left[\begin{array}{c}
\max \\
\left(x_{i j}\right)_{\alpha}^{L} \leq x_{i j} \leq\left(x_{i j}\right)_{\alpha}^{U} \\
\left(y_{r j}\right)_{\alpha}^{L} \leq y_{r j} \leq\left(y_{r j}\right)_{\alpha}^{U} \\
\forall i, j, r
\end{array}\right]\left\{\begin{array}{c}
\bar{w}_{k}=\max \sum_{r=1}^{s} u_{r} y_{r k}+u_{0} \\
\text { Sub to } \\
\sum_{i=1}^{m} v_{i} x_{i k}=1 \\
\sum_{r=1}^{s} u_{r} y_{r k}-\sum_{i=1}^{m} v_{i} x_{i j}+u_{0} \leq 0 ; \quad \forall j
\end{array}\right.
$$

Where $u_{r}, v_{i} \geq 0 \forall r, j$ and $\left[\left(x_{i j}\right)_{\alpha}^{L},\left(x_{i j}\right)_{\alpha}^{U}\right],\left[\left(y_{r j}\right)_{\alpha}^{L},\left(y_{r j}\right)_{\alpha}^{U}\right]$ are $\alpha$-level a form of the fuzzy inputs and fuzzy outputs respectively. The two-level mathematical model can be simplified to the conventional one-level model as follows:

$$
\left(W_{k}\right)_{\alpha}^{L}=\max \sum_{r=1}^{s} u_{r}\left(y_{r k}\right)_{\alpha}^{L}+u_{0}
$$

Sub to

$$
\begin{aligned}
& \sum_{r=1}^{s} u_{r}\left(y_{r k}\right)_{\alpha}^{L}-\sum_{i=1}^{m} v_{i}\left(x_{i k}\right)_{\alpha}^{U}+u_{0} \leq 0 \\
& \sum_{r=1}^{s} u_{r}\left(y_{r j}\right)_{\alpha}^{U}-\sum_{i=1}^{m} v_{i}\left(x_{i j}\right)_{\alpha}^{L}+u_{0} \leq 0 \\
& \sum_{j=1}^{m} v_{i}\left(x_{i k}\right)_{\alpha}^{U}=1, \quad u_{r}, v_{i} \geq 0, \forall r, i
\end{aligned}
$$

Similarly, upper bounds of fuzzy DEA model are given as:

$$
\left(W_{k}\right)_{\alpha}^{U}=\max \sum_{r=1}^{s} u_{r}\left(y_{r k}\right)_{\alpha}^{U}+u_{0}
$$

Sub to

$$
\begin{aligned}
& \sum_{r=1}^{s} u_{r}\left(y_{r k}\right)_{\alpha}^{U}-\sum_{i=1}^{m} v_{i}\left(x_{i k}\right)_{\alpha}^{L}+u_{0} \leq 0 \\
& \sum_{r=1}^{s} u_{r}\left(y_{r j}\right)_{\alpha}^{L}-\sum_{i=1}^{m} v_{i}\left(x_{i j}\right)_{\alpha}^{U}+u_{0} \leq 0 \\
& \sum_{j=1}^{m} v_{i}\left(x_{i k}\right)_{\alpha}^{L}=1, \quad u_{r}, v_{i} \geq 0, \forall r, i
\end{aligned}
$$

The above membership function is built by solving the lower and upper bounds $\left[\left(W_{k}\right)_{\alpha}^{L},\left(W_{k}\right)_{\alpha}^{U}\right]$ of the $\alpha$-level for each DMU using models see (Emrouznejad et al. (2014)). Saati et al. (2002) developed a fuzzy CCR model on the base of a possibility programming problem and later it was transformed into an interval programming problem using the $\alpha$-level approach the solution of interval programming can be solved as crisp of a model for a given $\alpha$ with some variable substitutions. The new developed 
DEA-model is derived for a particular case, where the inputs and outputs are triangular fuzzy numbers is as given below:

$$
\operatorname{Max} W_{k}=\sum_{r=1}^{s} y_{r k}^{\prime}
$$

Sub to

$$
\begin{aligned}
& \sum_{r=1}^{s} y_{r j}^{\prime}-\sum_{i=1}^{m} x_{i j}^{\prime} \leq 0 \forall j=1,2,3, \ldots, n \\
& v_{i}\left(\alpha x_{i j}^{m}+(1-\alpha) x_{i j}^{l}\right) \leq x_{i j}^{\prime} \leq v_{i}\left(\alpha x_{i j}^{m}+(1-\alpha) x_{i j}^{u}\right) \quad \forall i, j \\
& u_{r}\left(\alpha y_{r j}^{m}+(1-\alpha) y_{r j}^{l}\right) \leq y_{r j}^{\prime} \leq u_{r}\left(\alpha y_{r j}^{m}+(1-\alpha) y_{r j}^{u}\right) \forall r, j \\
& \sum_{i=1}^{m} x_{i k}^{\prime}=1, u_{r}, v_{i} \geq 0 \forall r=1,2,3, \ldots, s \text { and } i=1,2,3, \ldots m .
\end{aligned}
$$

Where $\tilde{x}_{i j}=\left(x_{i j}^{l}, x_{i j}^{m}, x_{i j}^{u}\right)$ and $\tilde{y}_{r j}=\left(y_{r j}^{l}, y_{r j}^{m}, y_{r j}^{u}\right)$ are the triangular fuzzy inputs and the triangular fuzzy outputs, $x_{i j}^{\prime}$ and $y_{r j}^{\prime}$ are the decision variables obtained from variable substitution used to transform the original fuzzy model into a parametric linear programming model with $\alpha \in(0,1)$. In Liu (2008) consider the relative importance of inputs and outputs as:

$\frac{L_{I \delta}}{U_{I q}} \leq \frac{v_{\delta}}{v_{q}} \leq \frac{U_{I \delta}}{L_{I q}}, \delta<q=2,3, \ldots, m$ and $\frac{L_{o \delta}}{U_{o q}} \leq \frac{u_{\delta}}{u_{q}} \leq \frac{U_{o \delta}}{L_{0 q}}, \delta<q=2,3, \ldots, s$ respectively.

Then Liu (2008) proposed two parametric mathematical programs are as given below:

$$
\left(W_{k}\right)_{\alpha}^{L}=\operatorname{Max} \sum_{r=1}^{s} u_{r}\left(y_{r p}\right)_{\alpha}^{L}
$$

Sub to

$$
\begin{aligned}
& \sum_{r=1}^{s} u_{r}\left(y_{r j}\right)_{\alpha}^{U}-\sum_{i=1}^{m} v_{i}(x i j)_{\alpha}^{L} \leq 0, \forall j, j \neq k \\
& -\mathrm{v}_{\delta}+I_{\delta_{q}}^{L} v_{q} \leq 0, v_{\delta}-I_{\delta_{q}}^{U} v_{q} \leq 0, \forall \delta<q \\
& -u_{\delta}+O_{\delta_{q}}^{L} u_{q} \leq 0, u_{\delta}-O_{\delta_{q}}^{U} u_{q} \leq 0, \forall \delta<q \\
& \sum_{i=1}^{m} v_{i}\left(x_{i k}\right)_{\alpha}^{U}=1 ; u_{r}, v_{i} \geq 0, \forall r, j . \\
\left(W_{k}\right)_{\alpha}^{U}= & \operatorname{Max} \sum_{r=1}^{s} u_{r}\left(y_{r k}\right)_{\alpha}^{U}
\end{aligned}
$$

Sub to

$$
\begin{aligned}
& \sum_{r=1}^{s} u_{r}\left(y_{r j}\right)_{\alpha}^{L}-\sum_{i=1}^{m} v_{i}\left(x_{i j}\right)_{\alpha}^{U} \leq 0, \forall j, j \neq k \\
& -\mathrm{v}_{\delta}+I_{\delta_{q}}^{L} v_{q} \leq 0, v_{\delta}-I_{\delta_{q}}^{U} v_{q} \leq 0, \forall \delta<q \\
& -u_{\delta}+O_{\delta_{q}}^{L} u_{q} \leq 0, u_{\delta}-O_{\delta_{q}}^{U} u_{q} \leq 0, \forall \delta<q \\
& \sum_{i=1}^{m} v_{i}\left(x_{i k}\right)_{\alpha}^{L}=1 ; u_{r}, v_{i} \geq 0, \forall r, j .
\end{aligned}
$$


Where $I_{\alpha_{q}}^{L}=\frac{L_{I \delta}}{U_{\delta_{q}}}, I_{\delta_{q}}^{U}=\frac{U_{1 \delta}}{L_{i q}}, O_{\delta_{q}}^{L}=\frac{L_{o \delta}}{U_{0 q}}$ and $O_{\delta q}^{L}=\frac{U_{o \delta}}{L_{o q}}$. In this paper, we use the only $\alpha$-level approach for solving the fuzzy CCR and BCC DEA-models. Apart from this we developed fuzzy slack based measure (FSBM), fuzzy super efficiency model (FSFM) and fuzzy networking DEA-model (FNDEA) using $\alpha$-level an approach which is discussed in this upcoming sections.

\section{Fuzzy slack-based measure (FSBM) measure of efficiency}

Let $x_{i j} ; i=1,2,3, . ., m$ and $y_{r j} ; r=1,2,3, \ldots, s$ be the $i^{\text {th }}$-input and $r^{\text {th }}$-output of $j^{\text {th }}-D M U ; j=1,2,3, \ldots, n$ respectively. It is assumed that the data set is known and strictly positive. In Tone (2001) proposed a non-oriented and non-radial DEA technique called slack based (SBM) measure through which we can Minimizing the inefficiency rate directly by make the user input and output slacks. The mathematical formulation of $\mathrm{SBM}$ is given below:

$\operatorname{Min} \tau_{k}=t-\frac{1}{m} \sum_{i=1}^{m} \frac{S_{i}^{-}}{x_{i 0}}$

Sub to

$$
\begin{gathered}
t+\frac{1}{s} \sum_{r=1}^{s} \frac{S_{r}^{+}}{y_{r 0}} \\
\sum_{j=1}^{n} \lambda_{j}^{\prime} x_{i j}+S_{i}^{-}=t x_{i 0} ; i=1,2,3, \ldots, m . \\
\sum_{j=1}^{n} \lambda_{j}^{\prime} y_{r j}-S_{r}^{+}=t y_{r 0} ; r=1,2,3, \ldots, s . \\
S_{i}^{-}=t s_{i}^{-} \geq 0 ; S_{r}^{+}=t s_{r}^{+} \geq 0 ; t \geq 0 \text { and } \lambda_{j}^{\prime}=\frac{\lambda_{j}}{t} \geq 0
\end{gathered}
$$

The above model is based on the assumption that input and output data are fixed, known and strictly positive. This is not possible always in the real world. Sometimes input and output data are known, positive but fuzzy type. In such situations, the model (4.1) is unable to produce any veiled information regarding the efficiency of DMUs. Let us assume $\tilde{x}_{i j}$ are the $i^{\text {th }}$ fuzzy input $i=1,2,3, \ldots, m$ and $\tilde{y}_{r j}$ are $r^{\text {th }}$ the fuzzy output $r=1,2,3, \ldots, s$ of $j^{\text {th }}$ DMU $j=1,2,3, \ldots, n$. In order to solve the fuzzy input and fuzzy outputs, we are defining the corresponding membership functions $\mu_{\tilde{x}_{i j}}$ and $\mu_{\tilde{y}_{r j}}$ for $\tilde{x}_{i j}$ fuzzy inputs and $\tilde{y}_{r j}$ fuzzy outputs respectively. Then the mathematically model for fuzzy inputs and fuzzy outputs on the bases of respective slacks are as: 
$\operatorname{Min} \tilde{\tau}_{k}=t-\frac{1}{m} \sum_{i=1}^{m} \frac{S_{i}^{-}}{\tilde{x}_{i k}}$

Sub to

$$
\begin{aligned}
& t+\frac{1}{s} \sum_{r=1}^{s} \frac{S_{r}^{+}}{\tilde{y}_{r k}}=1 \\
& \sum_{j=1}^{n} \tilde{x}_{i j} \lambda_{j}^{\prime}-S_{r}^{+}=t \tilde{x}_{i k} \forall i=1,2,3, \ldots, m \\
& \sum_{j=1}^{n} \tilde{y}_{r j} \lambda_{j}^{\prime}+S_{r}^{+}=t \tilde{y}_{r k} \forall r=1,2,3 \ldots, s \\
& \sum_{j=1}^{n} \lambda_{j}^{\prime}=t ; \forall t \geq 0 \\
& \lambda_{j}^{\prime} \geq 0 \forall j=1,2,3, \ldots, n \\
& S_{i}^{-} \geq 0, \text { and } S_{r}^{+} \geq 0 .
\end{aligned}
$$

Where $\tilde{\rho}_{k}$ fuzzy efficiency value of $k^{\text {th }}-D M U$. The optimal solution of the fuzzy SBM model (4.2) can be estimated by using a two-level mathematical model. The two levels are using to calculate the lower and upper bounds of the fuzzy DEA model and efficiency scores for a specific $\alpha$-level as follow:

$$
\left(\tau_{k}\right)_{\alpha}^{U}\left(\begin{array}{c}
\text { Min } t-\frac{1}{m} \sum_{i=1}^{m} \frac{S_{i}^{-}}{x_{i k}} \\
\left(x_{i j}\right)_{\alpha}^{L} \leq x_{i j} \leq\left(x_{i j}\right)_{\alpha}^{U} \\
\left(y_{r j}\right)_{\alpha}^{L} \leq y_{r j} \leq\left(y_{r j}\right)_{\alpha}^{U} \\
\forall i, j, r
\end{array} \mid \begin{array}{c}
\text { Sub to } \\
t+\frac{1}{S} \sum_{r=1}^{s} \frac{S_{r}^{+}}{y_{r k}}=1 \\
\sum_{j=1}^{n} x_{i j} \lambda_{j}^{\prime}+S_{i}^{-}=t x_{i k} \forall i=1,2,3, \ldots m \\
\sum_{j=1}^{n} y_{r j} \lambda_{j}^{\prime}-S_{r}^{+}=t y_{r k} \forall r=1,2,3, \ldots, s \\
\sum_{j=1}^{n} \lambda_{j}^{\prime}=t ; \forall t>0 \\
\lambda_{j}^{\prime} \geq 0 ; \forall j=1,2,3, \ldots, n \\
S_{r}^{+} \geq 0 \text { and } S_{i}^{-} \geq 0 .
\end{array}\right.
$$




$$
\left(\tau_{k}\right)_{\alpha}^{L}\left|\begin{array}{c}
\text { Min } t-\frac{1}{m} \sum_{i=1}^{m} \frac{S_{i}^{-}}{x_{i k}} \\
\text { Sub to } \\
\left(x_{i j}\right)_{\alpha}^{L} \leq x_{i j} \leq\left(x_{i j}\right)_{\alpha}^{U} \\
\left(y_{r j}\right)_{\alpha}^{L} \leq y_{r j} \leq\left(y_{r j}\right)_{\alpha}^{U} \\
\forall i, j, r
\end{array}\right| \begin{gathered}
\sum_{r=1}^{s} \frac{1}{y_{r k}} S_{r}^{+} \\
\sum_{j=1}^{n} x_{i j} \lambda_{j}^{\prime}+S_{i}^{-}=t x_{i k} \forall i=1,2,3, \ldots m \\
\sum_{j=1}^{n} y_{r j} \lambda_{j}^{\prime}-S_{r}^{+}=t y_{r k} \forall r=1,2,3, \ldots, s \\
\sum_{j=1}^{n} \lambda_{j}^{\prime}=t ; \forall t>0 \\
\lambda_{j}^{\prime} \geq 0 ; \forall j=1,2,3, \ldots, n \\
S_{r}^{+} \geq 0 \text { and } S_{i}^{-} \geq 0 .
\end{gathered}
$$

Where $\left[\left(x_{i j}\right)_{\alpha}^{L},\left(x_{i j}\right)_{\alpha}^{U}\right],\left[\left(y_{r j}\right)_{\alpha}^{L},\left(y_{r j}\right)_{\alpha}^{U}\right]$ are $\alpha$-level the form of the fuzzy inputs and fuzzy outputs respectively.

\section{Fuzzy SBM model for supper efficiency in DEA}

The super-efficiency for $n$-DMUsusing $m$-inputs and $s$-outputs can define as let $\tilde{x}_{i j}$ and denotes $i^{\text {th }}$ fuzzy input $i=1,2,3, \ldots, m$ and $r^{\text {th }}$ output $r=1,2,3, \ldots, s$ respectively of the $j^{\text {th }} \operatorname{DMU}(j=1,2,3, \ldots, n)$. The super-efficiency can be calculated by using the mathematical model as given below, under the assumption that $D M U_{k}$ should be efficient.

$\operatorname{Min} \tilde{\tau}_{k}=\frac{1}{m} \sum_{i=1}^{m} \frac{\bar{x}_{i}^{\prime}}{\tilde{x}_{i k}}$

Sub to

$$
\begin{aligned}
& \frac{1}{s} \sum_{i=1}^{s} \frac{\bar{y}_{r}^{\prime}}{\tilde{y}_{r k}}=1 \\
& \sum_{j=1, j \neq 1}^{n} \tilde{x}_{r j} \lambda_{j}^{\prime}+S_{i}^{-}=\bar{x}_{i}^{\prime} \forall i=1,2,3, \ldots, m \\
& \sum_{j=1, j \neq 1}^{n} \tilde{y}_{r j} \lambda_{j}^{\prime}-S_{r}^{+}=\bar{y}_{r}^{\prime} \forall r=1,2,3, \ldots, s \\
& \sum_{j=1, j \neq 1}^{n} \lambda_{j}^{\prime}=t \forall t>0
\end{aligned}
$$


Fuzzy Data Envelopment Analysis with SBM using a-level Fuzzy Approach

$$
\begin{aligned}
& \lambda_{j}^{\prime} \geq 0 ; \forall j=1,2,3, \ldots, n, j \neq k \\
& \bar{x}_{i}^{\prime} \geq t \tilde{x}_{i k}, 0 \leq \bar{y}_{r}^{\prime} \leq t \tilde{y}_{r k} \\
& S_{i}^{-} \geq 0 \text { and } S_{r}^{+} \geq 0 .
\end{aligned}
$$

The optimal solution of the SBM fuzzy Supper efficiency model (5.1) can be estimated by using a two-level mathematical model. The two levels are using to calculate the lower and upper bounds of fuzzy super efficiency of above model and an efficiency scores for a specific $\alpha$-level as follow:

$$
\left(\tilde{\tau}_{k}\right)_{\alpha}^{U}=\operatorname{Min} \frac{1}{m} \sum_{i=1}^{m} \frac{\left(\bar{x}_{i}^{\prime}\right)^{L}}{\left(x_{i k}\right)_{\alpha}^{L}}
$$

Sub to

$$
\begin{aligned}
& \frac{1}{s} \sum_{r=1}^{s} \frac{\left(\bar{y}_{r}^{\prime}\right)^{U}}{\left(y_{r k}\right)_{\alpha}^{U}}=1 \\
& \sum_{j=1, j \neq k}^{n}\left(x_{i k}\right)_{\alpha}^{L} \lambda_{j}^{\prime}+S_{i}^{-}=\left(\bar{x}_{i}^{\prime}\right)^{L} \forall i=1,2,3, \ldots, m . \\
& \sum_{j=1, j \neq k}^{n}\left(y_{r k}\right)_{\alpha}^{U} \lambda_{j}^{\prime}-S_{r}^{+}=\left(\bar{y}^{\prime}\right)^{U} \forall r=1,2,3, \ldots, s \\
& \sum_{j=1, j \neq k}^{n} \lambda_{j}^{\prime}=t \forall t>0 \\
& \lambda_{j}^{\prime} \geq 0 \forall j=1,2,3, \ldots n, j \neq k \\
& \left(\bar{x}^{\prime}\right)^{L} \geq t\left(x_{i k}\right)_{\alpha}^{L}, 0 \leq\left(\bar{y}_{r}^{\prime}\right)^{U} \leq t\left(y_{r k}\right)_{\alpha}^{U} \\
& S_{i}^{-} \geq 0 \text { and } S_{r}^{+} \geq 0 .
\end{aligned}
$$

Similarly, upper bounds of fuzzy Supper efficiency model in DEA and efficiency scores for a specific $\alpha$-level as follow:

$$
\left(\tilde{\tau}_{k}\right)_{\alpha}^{L}=\operatorname{Min} \frac{1}{m} \sum_{i=1}^{m} \frac{\left(\vec{x}_{i}^{\prime}\right)^{U}}{\left(x_{i k}\right)_{\alpha}^{U}}
$$

Sub to

$$
\begin{aligned}
& \frac{1}{s} \sum_{r=1}^{s} \frac{\left(\bar{y}_{r}^{\prime}\right)^{L}}{\left(y_{r k}\right)_{\alpha}^{L}}=1 \\
& \sum_{j=1, j \neq k}^{n}\left(x_{i k}\right)_{\alpha}^{U} \lambda_{j}^{\prime}+S_{i}^{-}=\left(\bar{x}_{i}^{\prime}\right)^{U} \forall i=1,2,3, \ldots, m \\
& \sum_{j=1, j \neq k}^{n}\left(y_{r k}\right)_{\alpha}^{L} \lambda_{j}^{\prime}-S_{r}^{+}=\left(\bar{y}_{r}^{\prime}\right)^{L} \forall r=1,2,3, \ldots, s \\
& \sum_{j=1, j \neq k}^{n} \lambda_{j}^{\prime}=t \forall t>0
\end{aligned}
$$




$$
\begin{aligned}
& \lambda_{j}^{\prime} \geq 0 \forall j=1,2,3, \ldots n, j \neq k \\
& \left(\bar{x}^{\prime}\right)^{U} \geq t\left(x_{i k}\right)_{\alpha}^{U}, 0 \leq\left(\bar{y}_{r}^{\prime}\right)^{L} \leq t\left(y_{r k}\right)_{\alpha}^{L} \\
& S_{i}^{-} \geq 0 \text { and } S_{r}^{+} \geq 0 .
\end{aligned}
$$

It is not easy to determine the ranking through model (5.2) and model (5.3), because the outcome of the above models is also fuzzy numbers and different from the outcomes of the conventional DEA models. Then Chen and Klien (1997) proposed the area measurement method to rank the fuzzy numbers at unknown membership function. Thus we are using the $\alpha$-level approach to obtain the ranking of DMUs. Our aim is to split the area into $\mathrm{m}$. where $\mathrm{m}$ is equal to infinity by using $\alpha_{i}=\frac{i h}{m} ; i=0,1,2, \ldots, m$, where $\mathrm{h}$ is the maximum height of membership function. Then we can obtain the rank of the DMUs having fuzzy inputs and fuzzy outputs using the following equation:

$$
I\left(\tilde{\tau}_{k}, \tilde{R}\right)=\lim _{m \rightarrow \infty}\left(\frac{\sum_{i=1}^{m}\left[\left(\tau_{k}\right)_{\alpha_{i}}^{U}-c\right]}{\sum_{i=1}^{m}\left[\left(\tau_{k}\right)_{\alpha_{i}}^{U}-c\right]-\sum_{i=1}^{m}\left[\left(\tau_{k}\right)_{\alpha_{i}}^{L}-d\right]}\right)
$$

Where $c=\operatorname{Min}_{i, k}\left\{\left(\tau_{k}\right)_{\alpha_{i}}\right\}, d=\operatorname{Max}_{i, k}\left\{\left(\tau_{k}\right)_{\alpha_{i}}\right\}$, if $I\left(\tilde{\tau}_{k}, \tilde{R}\right)$ is higher than the represented the $k^{\text {th }}$ DMU ranking is higher.

\section{Fuzzy SBM models in case of three-stage network structure}

Suppose we have $n-D M U s$, where each $D M U_{j}(j=1,2,3, \ldots, n)$ is assessing m-fuzzy inputs in the form of $\tilde{x}_{i j}(i=1,2,3, \ldots, m)$ in order to produce the final s fuzzy outputs in the form $\tilde{y}_{r j}(r=1,2,3, \ldots, s)$. Where the production operations of DMU are passing through in three stages namely as input, intermediate and output stage connected in series. While as in the intermediate has two sub-stages $\mathrm{A}$ and $\mathrm{B}$ which are connected parallel in the processing system as shown in Figure 6.1.

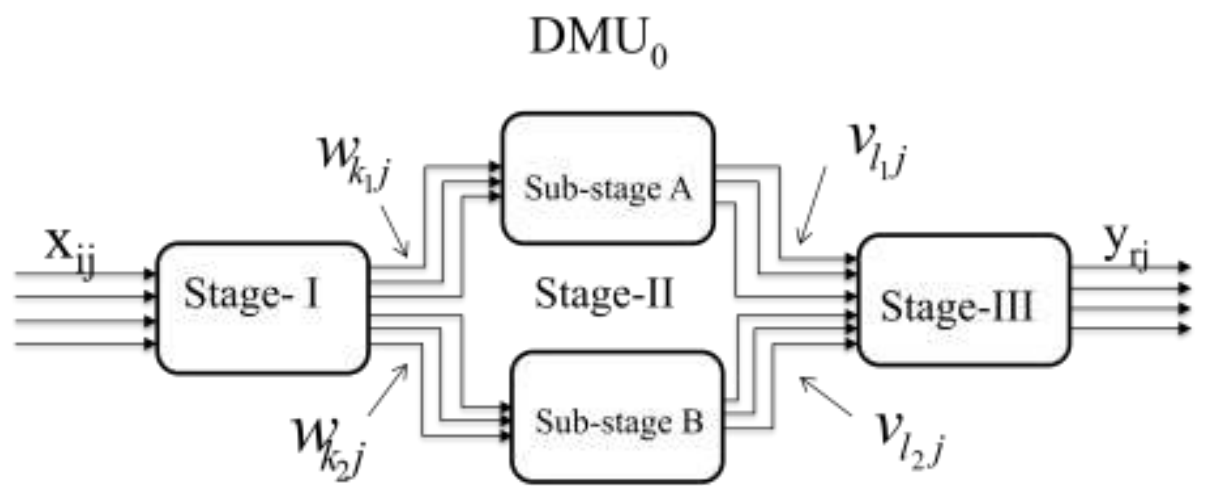

Figure 6.1: Network Structure 
For better understanding of the distribution of inputs for each stage and sub stage, let $\tilde{x}_{i j}$ be the input for stage one in the above diagram to produce the output $\widetilde{w}_{k_{1} j}$ and $\widetilde{w}_{k_{2} j}$ which in turn represent inputs for sub-stages A and B under stage two. Additionally, the output $\tilde{v}_{l_{1} j}$ and $\tilde{v}_{l_{2} j}$ of sub-stage A and B represent as inputs for stage three to generate the final output $\tilde{y}_{r j}$.

$$
\left(\tilde{\tau}_{k}\right) \text { overall }=\text { Min } t-\frac{1}{m} \sum_{i=1}^{m} \frac{S_{i}^{-}}{\tilde{x}_{i k}}
$$

Sub to

$$
\begin{aligned}
& t+\frac{1}{s} \sum_{r=1}^{s} \frac{S_{r}^{+}}{\tilde{y}_{r k}}=1 \\
& \sum_{j=1}^{n} \lambda_{j}^{\prime} \tilde{x}_{i j}+S_{r}^{+}=t \tilde{x}_{i k} ; i=1,2,3, . ., m . \\
& \sum_{j=1}^{n} \eta_{j}^{\prime} \tilde{y}_{r j}-S_{r}^{+}=t y_{r k} ; r=1,2,3, \ldots, s . \\
& \sum_{j=1}^{n} \lambda_{j}^{\prime} \tilde{w}_{k j}=\sum_{j=1}^{n} \mu_{j}^{\prime 1} \tilde{w}_{k_{1} j}+\sum_{j=1}^{n} \mu_{j}^{\prime 2} \tilde{w}_{k_{2} j} ; k_{1}, k_{2} \subseteq k . \\
& \sum_{j=1}^{n} \mu_{j}^{\prime 1} \tilde{v}_{l_{1} j}+\sum_{j=1}^{n} \mu_{j}^{\prime 2} \tilde{v}_{l_{2} j}=\sum_{j=1}^{n} \eta_{j}^{\prime} \tilde{v}_{l} j ; l_{1}, l_{2} \subseteq l . \\
& \sum_{j=1}^{n} \lambda_{j}^{\prime}=\sum_{j=1}^{n} \mu_{j}^{\prime 1}=\sum_{j=1}^{n} \mu_{j}^{\prime 2}=\sum_{j=1}^{n} \eta_{j}^{\prime}=t ; \forall t>0 \\
& \lambda_{j}^{\prime} \geq 0, \mu_{j}^{\prime 1} \geq 0, \mu_{j}^{\prime 2} \geq 0, \text { and } \eta_{j}^{\prime} \geq 0 \forall j=1,2,3, \ldots, n \\
& S_{i}^{-} \geq 0 \text { and } S_{r}^{+} \geq 0 .
\end{aligned}
$$

We can use of $\alpha$-level the fuzzy approach for estimating lower and upper bounds of networking fuzzy SBM model. In all the above-mentioned approaches of handling the fuzzy data in DEA, the role of the fuzzy arithmetic is very much important in DEA terminology. The fuzziness in DEA crates complexity in order to use fuzzy equalities and fuzzy inequalities i.e. $(\tilde{\leq}, \cong, \tilde{\geq})$.

\section{Numerical illustration}

In this section, we present a numerical example based on 24 banks as DMUs using Assets, Expense, and Deposit as inputs while as fees, amount of loans, and amount of investments are used as output. In order to illustrate the use of the methodology proposed here like fuzzy BCC, fuzzy SBM and fuzzy Super SMB. We treat the two outputs amount of loans and investments are as fuzzy items and analyze the efficiency of the banking sector with triangles fuzzy functions from the fuzzy theory. The data are taken from $(\mathrm{Li}$, 2003), and recorded in Table 1. 
Table 1: Inputs and Output of 24 DMUs

\begin{tabular}{|c|c|c|c|c|c|c|}
\hline Banks & $\begin{array}{c}\text { Asset } \\
\text { s }\end{array}$ & $\begin{array}{c}\text { Expens } \\
\text { e }\end{array}$ & Deposit & Fees & Amount of loans & Amount of investments \\
\hline DMU1 & 25026 & 7358 & $\begin{array}{c}105019 \\
0\end{array}$ & 3815 & {$[904559,921046,937533]$} & $\begin{array}{c}\text { [203176, 203176, } \\
250329]\end{array}$ \\
\hline DMU2 & 23601 & 8888 & $\begin{array}{c}128733 \\
0\end{array}$ & 7960 & $\begin{array}{c}{[1063486,1079681,} \\
1095876]\end{array}$ & $\begin{array}{c}330262,330262, \\
346398]\end{array}$ \\
\hline DMU3 & 23000 & 9078 & $\begin{array}{c}131837 \\
1\end{array}$ & 6654 & $\begin{array}{c}{[1047592,1063761,} \\
1079930]\end{array}$ & $\begin{array}{c}{[301602,316244,} \\
323712]\end{array}$ \\
\hline DMU4 & 1319 & 1432 & 29834 & 314 & {$[83867,85570,87273]$} & $\begin{array}{c}171508,180588, \\
180588]\end{array}$ \\
\hline DMU5 & 14887 & 8718 & $\begin{array}{c}128929 \\
0\end{array}$ & 7030 & $\begin{array}{c}1191878,1203917 \\
1215956]\end{array}$ & $\begin{array}{c}286645,312260, \\
312260]\end{array}$ \\
\hline DMU6 & 3807 & 1043 & 152379 & 362 & {$[129055,132053,135051]$} & {$[5072,7103,10286]$} \\
\hline DMU7 & 3785 & 1965 & 240894 & 783 & {$[191531,194883,198235]$} & {$[6866,12479,13603]$} \\
\hline DMU8 & 35017 & 12143 & $\begin{array}{c}110024 \\
3\end{array}$ & $\begin{array}{c}2466 \\
1\end{array}$ & {$[792452,803948,815444]$} & $\begin{array}{c}\text { [345454, 345454, } \\
416233]\end{array}$ \\
\hline DMU9 & 27656 & 6485 & $\begin{array}{c}105551 \\
8\end{array}$ & 6434 & {$[754371,765703,777035]$} & $\begin{array}{c}{[371145,371145,} \\
402658]\end{array}$ \\
\hline $\begin{array}{l}\text { DMU1 } \\
0\end{array}$ & 13261 & 5753 & 835647 & 9488 & {$[654397,662278,670159]$} & $\begin{array}{c}{[135195,139419,} \\
145389]\end{array}$ \\
\hline $\begin{array}{c}\text { DMU1 } \\
1 \\
\end{array}$ & 14734 & 6263 & 945385 & 2333 & {$[824971,843270,861569]$} & $\begin{array}{c}{[109295,109295,} \\
129384]\end{array}$ \\
\hline $\begin{array}{l}\text { DMU1 } \\
2 \\
\end{array}$ & 2932 & 1162 & 130526 & 461 & {$[110392,112496,114600]$} & {$[26993,33004,33004]$} \\
\hline $\begin{array}{c}\text { DMU1 } \\
3\end{array}$ & 6847 & 4316 & 158200 & 1392 & {$[113777,119955,126133]$} & {$[2730,2773,14283]$} \\
\hline $\begin{array}{c}\text { DMU1 } \\
4\end{array}$ & 8564 & 2562 & 286768 & 2274 & {$[202733,207697,212661]$} & {$[55026,73313,80389]$} \\
\hline $\begin{array}{l}\text { DMU1 } \\
5\end{array}$ & 9075 & 6063 & 811336 & 4744 & {$[596510,608249,619988]$} & $\begin{array}{c}{[117013,160938,} \\
257146]\end{array}$ \\
\hline $\begin{array}{l}\text { DMU1 } \\
6\end{array}$ & 12497 & 3441 & 621534 & 3993 & {$[512517,517119,521721]$} & $\begin{array}{c}{[141648,157706,} \\
157706]\end{array}$ \\
\hline $\begin{array}{l}\text { DMU1 } \\
7\end{array}$ & 2266 & 2789 & 273644 & 1404 & {$[237782,240963,244144]$} & $\begin{array}{c}22989,22989 \\
31440.571] \\
\end{array}$ \\
\hline $\begin{array}{l}\text { DMU1 } \\
8 \\
\end{array}$ & 16748 & 7077 & 730199 & 8427 & {$[553686,564928,576170]$} & {$[60778,69933,72253]$} \\
\hline $\begin{array}{l}\text { DMU1 } \\
9 \\
\end{array}$ & 2474 & 2104 & 281299 & 2265 & {$[220223,225754,231285]$} & {$[27526,31041,31041]$} \\
\hline $\begin{array}{c}\text { DMU2 } \\
0 \\
\end{array}$ & 2986 & 2642 & 240961 & 2883 & {$[215084,219272,223460]$} & {$[21755,21755,30946]$} \\
\hline $\begin{array}{c}\text { DMU2 } \\
1\end{array}$ & 3759 & 1232 & 209383 & 1086 & {$[181589,186207,190825]$} & {$[37699,40444,43115]$} \\
\hline $\begin{array}{l}\text { DMU2 } \\
2 \\
\end{array}$ & 9393 & 2774 & 329084 & 2228 & {$[273626,278783,283940]$} & {$[34529,36961,38520]$} \\
\hline $\begin{array}{c}\text { DMU2 } \\
3\end{array}$ & 5168 & 1775 & 214344 & 1894 & {$[161365,168898,176431]$} & {$[15310,17665,25309]$} \\
\hline $\begin{array}{l}\text { DMU2 } \\
4\end{array}$ & 33864 & 11836 & $\begin{array}{c}199865 \\
4\end{array}$ & 3801 & $\begin{array}{c}{[1716538,1745691,} \\
1774844]\end{array}$ & $\begin{array}{c}{[162436,162436,} \\
164595]\end{array}$ \\
\hline
\end{tabular}

From the analysis, it was observed that out 24 DMUs (Banks) only 13 DMUs are performer efficiently are having efficiency scores equal to 1 : DMUs 4, 5, 6, 8, 9, 10, 12, $16,17,19,20,21$, and 24. While as 11 DMUs are performing inefficiently and having efficiency scores less than (>1): DMUs 1, 2, 3, 7, 11, 13, 14, 15, 18, 22, and 24 under the fuzzy BCC model on the different levels of $\alpha$ from (0 to 1). 
Table 2: Lower Bounds of inefficient DMUs by FBCC with $\alpha$-level Approach

\begin{tabular}{l|ccccccccccccc}
\hline \multirow{2}{*}{ DMUs } & \multicolumn{10}{c}{$\left(W_{k}\right)_{\alpha}^{L}=$ Lower limits of Fuzzy BCC efficiency on different levels of $\alpha$. } \\
\cline { 2 - 6 } & $\alpha=0.1$ & $\alpha=0.2$ & $\alpha=0.3$ & $\alpha=0.4$ & $\alpha=0.5$ & $\alpha=0.6$ & $\alpha=0.7$ & $\alpha=0.8$ & $\alpha=0.9$ & $\alpha=1.0$ \\
\hline DMU1 & 0.902 & 0.904 & 0.907 & 0.910 & 0.912 & 0.915 & 0.917 & 0.920 & 0.923 & 0.925 & 0.928 \\
DMU2 & 0.927 & 0.929 & 0.931 & 0.934 & 0.936 & 0.938 & 0.941 & 0.944 & 0.948 & 1.000 & 1.000 \\
DMU3 & 0.856 & 0.858 & 0.861 & 0.864 & 0.866 & 0.870 & 0.875 & 0.880 & 0.885 & 0.890 & 0.895 \\
DMU7 & 0.816 & 0.819 & 0.821 & 0.824 & 0.827 & 0.830 & 0.832 & 0.835 & 0.838 & 0.840 & 0.843 \\
DMU11 & 0.932 & 0.935 & 0.938 & 0.941 & 0.944 & 0.948 & 0.951 & 0.954 & 0.957 & 0.961 & 0.964 \\
DMU13 & 0.488 & 0.488 & 0.488 & 0.488 & 0.488 & 0.488 & 0.488 & 0.489 & 0.494 & 0.500 & 0.505 \\
DMU14 & 0.757 & 0.760 & 0.762 & 0.765 & 0.768 & 0.771 & 0.773 & 0.776 & 0.779 & 0.782 & 0.784 \\
DMU15 & 0.857 & 0.858 & 0.860 & 0.861 & 0.863 & 0.868 & 0.875 & 0.882 & 0.888 & 0.895 & 0.902 \\
DMU18 & 0.850 & 0.852 & 0.854 & 0.856 & 0.858 & 0.861 & 0.863 & 0.866 & 0.868 & 0.871 & 0.874 \\
DMU22 & 0.857 & 0.859 & 0.862 & 0.865 & 0.867 & 0.870 & 0.872 & 0.875 & 0.877 & 0.880 & 0.883 \\
DMU23 & 0.971 & 0.971 & 0.971 & 0.971 & 0.971 & 0.971 & 0.971 & 0.971 & 0.971 & 0.971 & 0.971 \\
\hline
\end{tabular}

Table 2: shows the lower bounds of inefficient DMUs under FBCC at different levels of $\alpha$. Table 3: shows the upper bounds results of FBCC model at ten different levels of $\alpha$ from 0 to 1 , for inefficient DMUs.

Table 3: Upper Bounds of inefficiency DMUs by FBCC with $\alpha$-level Approach

\begin{tabular}{l|lllllllllllll}
\hline \multirow{2}{*}{ DMUs } & \multicolumn{1}{c}{$\left(W_{k}\right)_{\alpha}^{U}=$ Upper limits of Fuzzy BCC efficiency on different levels of $\alpha$. } \\
\cline { 2 - 12 } & $\alpha=0$ & $\alpha=0.1$ & $\alpha=0.2$ & $\alpha=0.3$ & $\alpha=0.4$ & $\alpha=0.5$ & $\alpha=0.6$ & $\alpha=0.7$ & $\alpha=0.8$ & $\alpha=0.9$ & $\alpha=0.1$ \\
\hline DMU1 & 0.954 & 0.952 & 0.949 & 0.946 & 0.944 & 0.941 & 0.938 & 0.936 & 0.933 & 0.930 & 0.928 \\
DMU2 & 1.000 & 1.000 & 1.000 & 1.000 & 1.000 & 1.000 & 1.000 & 1.000 & 1.000 & 1.000 & 1.000 \\
DMU3 & 0.974 & 0.968 & 0.960 & 0.951 & 0.940 & 0.927 & 0.921 & 0.914 & 0.908 & 0.901 & 0.895 \\
DMU7 & 0.871 & 0.868 & 0.865 & 0.862 & 0.860 & 0.857 & 0.854 & 0.851 & 0.849 & 0.846 & 0.843 \\
DMU11 & 0.996 & 0.993 & 0.990 & 0.987 & 0.983 & 0.980 & 0.977 & 0.973 & 0.970 & 0.967 & 0.964 \\
DMU13 & 0.561 & 0.555 & 0.550 & 0.544 & 0.539 & 0.533 & 0.527 & 0.522 & 0.516 & 0.511 & 0.505 \\
DMU14 & 0.811 & 0.808 & 0.806 & 0.803 & 0.800 & 0.798 & 0.795 & 0.792 & 0.790 & 0.787 & 0.784 \\
DMU15 & 1.000 & 1.000 & 1.000 & 1.000 & 0.989 & 0.970 & 0.956 & 0.942 & 0.929 & 0.915 & 0.902 \\
DMU18 & 0.900 & 0.897 & 0.895 & 0.892 & 0.889 & 0.887 & 0.884 & 0.882 & 0.879 & 0.876 & 0.874 \\
DMU22 & 0.908 & 0.905 & 0.903 & 0.900 & 0.898 & 0.895 & 0.893 & 0.890 & 0.888 & 0.885 & 0.883 \\
DMU23 & 0.971 & 0.971 & 0.971 & 0.971 & 0.971 & 0.971 & 0.971 & 0.971 & 0.971 & 0.971 & 0.971 \\
\hline \hline
\end{tabular}

From fuzzy BCC model, it was observed 13 DMUs are efficient, however, in fuzzy SBM, only 11 DMUs are identified as efficient. DMU6 and DMU12 are excluding from the efficient class of DMUs under the Fuzzy SBM model.

Table 4: Lower Bounds of inefficiency DMUs by Fuzzy SBM with $\alpha$-level Approach

\begin{tabular}{c|ccccccccccccc}
\hline \multirow{2}{*}{ DMUs } & \multicolumn{10}{c}{$\left(\tau_{k}\right)_{\alpha}^{L}=$ Lower limits of Fuzzy SBM efficiency on different levels of $\alpha}$. \\
\cline { 2 - 14 } & $\alpha=0$ & $\alpha=0.1$ & $\alpha=0.2$ & $\alpha=0.3$ & 4 & 5 & 6 & 7 & $\alpha=0.8$ & $\alpha=0.9$ & 1 \\
\hline DMU1 & 0.56 & 0.568 & 0.570 & 0.572 & 0.574 & 0.576 & 0.578 & 0.579 & 0.581 & 0.583 & 0.585
\end{tabular}




\begin{tabular}{|c|c|c|c|c|c|c|c|c|c|c|c|}
\hline DMU2 & $\begin{array}{c}6 \\
0.83 \\
3\end{array}$ & 0.838 & 0.843 & 0.847 & 0.852 & 0.857 & 0.862 & 0.868 & 0.886 & 1.000 & 1.000 \\
\hline DMU3 & $\begin{array}{c}0.72 \\
6\end{array}$ & 0.730 & 0.733 & 0.737 & 0.740 & 0.744 & 0.747 & 0.750 & 0.754 & 0.758 & 0.766 \\
\hline DMU6 & $\begin{array}{c}0.99 \\
9\end{array}$ & 0.999 & 0.999 & 0.999 & 0.999 & 0.999 & 0.999 & 0.999 & 0.978 & 0.989 & 0.989 \\
\hline DMU7 & $\begin{array}{c}0.08 \\
9\end{array}$ & 0.096 & 0.103 & 0.111 & 0.118 & 0.125 & 0.132 & 0.140 & 0.147 & 0.154 & 0.161 \\
\hline $\begin{array}{l}\text { DMU1 } \\
1\end{array}$ & $\begin{array}{c}0.47 \\
0\end{array}$ & 0.471 & 0.473 & 0.474 & 0.476 & 0.479 & 0.481 & 0.484 & 0.486 & 0.489 & 0.491 \\
\hline $\begin{array}{l}\text { DMU1 } \\
2\end{array}$ & $\begin{array}{c}0.98 \\
9\end{array}$ & 0.999 & 0.999 & 0.999 & 0.997 & 0.999 & 0.999 & 0.999 & 0.988 & 0.989 & 0.989 \\
\hline $\begin{array}{l}\text { DMU1 } \\
3\end{array}$ & $\begin{array}{c}0.01 \\
9\end{array}$ & 0.019 & 0.019 & 0.019 & 0.019 & 0.019 & 0.019 & 0.019 & 0.019 & 0.019 & 0.020 \\
\hline $\begin{array}{l}\text { DMU1 } \\
4\end{array}$ & $\begin{array}{c}0.37 \\
0\end{array}$ & 0.380 & 0.389 & 0.398 & 0.407 & 0.416 & 0.425 & 0.434 & 0.443 & 0.451 & 0.459 \\
\hline $\begin{array}{l}\text { DMU1 } \\
5\end{array}$ & $\begin{array}{c}0.63 \\
8\end{array}$ & 0.652 & 0.666 & 0.679 & 0.692 & 0.704 & 0.716 & 0.728 & 0.739 & 0.751 & 0.761 \\
\hline $\begin{array}{l}\text { DMU1 } \\
8\end{array}$ & $\begin{array}{c}0.38 \\
5\end{array}$ & 0.391 & 0.398 & 0.404 & 0.411 & 0.417 & 0.423 & 0.430 & 0.436 & 0.443 & 0.449 \\
\hline $\begin{array}{l}\text { DMU2 } \\
2\end{array}$ & $\begin{array}{c}0.29 \\
3\end{array}$ & 0.295 & 0.298 & 0.300 & 0.303 & 0.306 & 0.308 & 0.311 & 0.313 & 0.316 & 0.319 \\
\hline $\begin{array}{l}\text { DMU2 } \\
3\end{array}$ & $\begin{array}{c}0.31 \\
4\end{array}$ & 0.319 & 0.324 & 0.330 & 0.335 & 0.340 & 0.345 & 0.350 & 0.355 & 0.360 & 0.366 \\
\hline
\end{tabular}

Table 5: Upper Bounds of inefficiency DMUs by Fuzzy SBM

\begin{tabular}{|c|c|c|c|c|c|c|c|c|c|c|c|}
\hline \multirow[b]{2}{*}{ DMUs } & \multicolumn{11}{|c|}{$\left(\tau_{k}\right)_{\alpha}^{U}=$ Upper limits of Fuzzy SBM efficiency on different levels of $\alpha$} \\
\hline & $\alpha=0$ & $\alpha=0.1$ & $\begin{array}{l}\alpha=0 . \\
2 \\
\end{array}$ & $\begin{array}{l}\alpha=0 . \\
3\end{array}$ & $\alpha=0.4$ & $\alpha=0.5$ & $\alpha=0.6$ & $\alpha=0.7$ & $\alpha=0.8$ & $\begin{array}{l}\alpha=0 . \\
9\end{array}$ & $\alpha=0.1$ \\
\hline DMU1 & $\begin{array}{c}0.65 \\
4\end{array}$ & 0.645 & $\begin{array}{c}0.63 \\
7\end{array}$ & $\begin{array}{c}0.62 \\
9\end{array}$ & 0.623 & 0.616 & 0.610 & 0.604 & 0.598 & $\begin{array}{c}0.59 \\
1\end{array}$ & 0.585 \\
\hline DMU2 & $\begin{array}{c}1.00 \\
0\end{array}$ & 1.000 & $\begin{array}{c}1.00 \\
0\end{array}$ & $\begin{array}{c}1.00 \\
0\end{array}$ & 1.000 & 1.000 & 1.000 & 1.000 & 1.000 & $\begin{array}{c}1.00 \\
0\end{array}$ & 1.000 \\
\hline DMU3 & $\begin{array}{c}0.91 \\
4\end{array}$ & 0.896 & $\begin{array}{c}0.87 \\
8\end{array}$ & $\begin{array}{c}0.86 \\
3\end{array}$ & 0.846 & 0.825 & 0.799 & 0.788 & 0.781 & $\begin{array}{c}0.77 \\
4\end{array}$ & 0.766 \\
\hline DMU6 & $\begin{array}{c}1.00 \\
0\end{array}$ & 1.000 & $\begin{array}{c}1.00 \\
0\end{array}$ & $\begin{array}{c}1.00 \\
0\end{array}$ & 1.000 & 1.000 & 1.000 & 1.000 & 1.000 & $\begin{array}{c}1.00 \\
0\end{array}$ & 1.000 \\
\hline DMU7 & $\begin{array}{c}0.19 \\
4\end{array}$ & 0.191 & $\begin{array}{c}0.18 \\
7\end{array}$ & $\begin{array}{c}0.18 \\
4\end{array}$ & 0.181 & 0.177 & 0.174 & 0.171 & 0.168 & $\begin{array}{c}0.16 \\
4\end{array}$ & 0.161 \\
\hline $\begin{array}{l}\text { DMU1 } \\
1\end{array}$ & $\begin{array}{c}0.57 \\
2\end{array}$ & 0.561 & $\begin{array}{c}0.55 \\
4\end{array}$ & $\begin{array}{c}0.54 \\
6\end{array}$ & 0.539 & 0.531 & 0.523 & 0.515 & 0.507 & $\begin{array}{c}0.49 \\
9\end{array}$ & 0.491 \\
\hline $\begin{array}{l}\text { DMU1 } \\
2\end{array}$ & $\begin{array}{c}1.00 \\
0\end{array}$ & 1.000 & $\begin{array}{c}1.00 \\
0\end{array}$ & $\begin{array}{c}1.00 \\
0\end{array}$ & 1.000 & 1.000 & 1.000 & 1.000 & 1.000 & $\begin{array}{c}1.00 \\
0\end{array}$ & 1.000 \\
\hline $\begin{array}{l}\text { DMU1 } \\
3\end{array}$ & $\begin{array}{c}0.09 \\
8\end{array}$ & 0.090 & $\begin{array}{c}0.08 \\
3\end{array}$ & $\begin{array}{c}0.07 \\
5\end{array}$ & 0.067 & 0.059 & 0.051 & 0.043 & 0.036 & $\begin{array}{c}0.02 \\
8\end{array}$ & 0.020 \\
\hline $\begin{array}{l}\text { DMU1 } \\
4\end{array}$ & $\begin{array}{c}0.51 \\
0\end{array}$ & 0.505 & $\begin{array}{c}0.50 \\
0\end{array}$ & $\begin{array}{c}0.49 \\
5\end{array}$ & 0.490 & 0.485 & 0.479 & 0.474 & 0.469 & $\begin{array}{c}0.46 \\
4\end{array}$ & 0.459 \\
\hline $\begin{array}{l}\text { DMU1 } \\
5\end{array}$ & $\begin{array}{c}1.00 \\
0\end{array}$ & 1.000 & $\begin{array}{c}1.00 \\
0\end{array}$ & $\begin{array}{c}1.00 \\
0\end{array}$ & 0.878 & 0.861 & 0.843 & 0.824 & 0.804 & $\begin{array}{c}0.78 \\
4\end{array}$ & 0.761 \\
\hline DMU1 & 0.47 & 0.475 & 0.47 & 0.46 & 0.466 & 0.463 & 0.461 & 0.458 & 0.455 & 0.45 & 0.449 \\
\hline
\end{tabular}


Fuzzy Data Envelopment Analysis with SBM using $\alpha$-level Fuzzy Approach

\begin{tabular}{|c|c|c|c|c|c|c|c|c|c|c|c|}
\hline 8 & 8 & & 2 & 9 & & & & & & 2 & \\
\hline $\begin{array}{l}\text { DMU2 } \\
2\end{array}$ & $\begin{array}{c}0.35 \\
4\end{array}$ & 0.350 & $\begin{array}{c}0.34 \\
6\end{array}$ & $\begin{array}{c}0.34 \\
3\end{array}$ & 0.339 & 0.335 & 0.332 & 0.328 & 0.325 & $\begin{array}{c}0.32 \\
2\end{array}$ & 0.319 \\
\hline $\begin{array}{l}\text { DMU2 } \\
3 \\
\end{array}$ & $\begin{array}{c}0.48 \\
9 \\
\end{array}$ & 0.477 & $\begin{array}{c}0.46 \\
5 \\
\end{array}$ & $\begin{array}{c}0.45 \\
3 \\
\end{array}$ & 0.441 & 0.429 & 0.417 & 0.404 & 0.391 & $\begin{array}{c}0.37 \\
9 \\
\end{array}$ & 0.366 \\
\hline
\end{tabular}

Efficient but performing weakly. In other words, we can say that there is a chance to improve efficiency by reducing the input and output slacks of DMU 6 and 12 respectively. Thus it was clear that fuzzy SBM has good discrimination power over fuzzy BCC. The results of Table 3 are the lower bounds of efficiency scores in fuzzy SBM model at different levels of $\alpha$. Table 4 shows the upper bounds of fuzzy SBM model at different levels of $\alpha$. In addition, we also observed that DMU2 is full efficient at $\alpha=1$, but when $\alpha=0$ it showing inefficiency. Thus in conventional DEA DMU2 is fully efficient, however, Bank 2 is not affected by its overdue loans ratio, and as such, its efficiency score is an overestimation.

Table 6: Lower Bounds of Supper efficiency DMUs by Fuzzy Supper SBM.

\begin{tabular}{l|ccccccccccc}
\hline \multirow{2}{*}{ DMUs } & \multicolumn{1}{c}{$\left(\tilde{\tau}_{k}\right)_{\alpha}^{L}=$ Lower limits of Fuzzy Super -SBM efficiency on different levels of $\alpha}$. \\
\cline { 2 - 13 } & $\alpha=0$ & $\alpha=0.1$ & $\alpha=0.2$ & $\alpha=0.3$ & $\alpha=0.4$ & $\alpha=0.5$ & $\alpha=0.6$ & $\alpha=0.7$ & $\alpha=0.8$ & $\alpha=0.9$ & $\alpha=0.1$ \\
\hline DMU4 & 3.466 & 3.467 & 3.469 & 3.470 & 3.472 & 3.473 & 3.475 & 3.476 & 3.478 & 3.479 & 3.481 \\
DMU5 & 1.155 & 1.142 & 1.155 & 1.165 & 1.174 & 1.181 & 1.190 & 1.198 & 1.206 & 1.212 & 1.217 \\
DMU8 & 1.304 & 1.305 & 1.306 & 1.307 & 1.307 & 1.308 & 1.309 & 1.310 & 1.311 & 1.312 & 1.313 \\
DMU9 & 1.081 & 1.083 & 1.085 & 1.087 & 1.089 & 1.091 & 1.092 & 1.094 & 1.096 & 1.098 & 1.100 \\
DMU10 & 1.065 & 1.066 & 1.066 & 1.067 & 1.068 & 1.068 & 1.069 & 1.070 & 1.071 & 1.071 & 1.072 \\
DMU16 & 1.037 & 1.038 & 1.040 & 1.041 & 1.042 & 1.043 & 1.045 & 1.046 & 1.047 & 1.049 & 1.050 \\
DMU17 & 1.041 & 1.043 & 1.044 & 1.045 & 1.046 & 1.048 & 1.049 & 1.050 & 1.051 & 1.053 & 1.054 \\
DMU19 & 1.103 & 1.105 & 1.106 & 1.108 & 1.109 & 1.111 & 1.112 & 1.114 & 1.115 & 1.116 & 1.118 \\
DMU20 & 1.073 & 1.074 & 1.075 & 1.077 & 1.078 & 1.079 & 1.081 & 1.109 & 1.083 & 1.084 & 1.086 \\
DMU21 & 1.076 & 1.078 & 1.080 & 1.081 & 1.083 & 1.085 & 1.087 & 1.089 & 1.091 & 1.093 & 1.095 \\
DMU24 & 1.108 & 1.108 & 1.109 & 1.110 & 1.111 & 1.112 & 1.112 & 1.113 & 1.114 & 1.115 & 1.115 \\
\hline \hline
\end{tabular}

Table 7: Upper Bounds of Supper efficiency DMUs by Fuzzy Supper SBM.

\begin{tabular}{c|cccccccccccc}
\hline \multirow{2}{*}{ DMUs } & \multicolumn{1}{c}{$\left(\tilde{\tau}_{k}\right)_{\alpha}^{U}=$ Upper limits of Fuzzy Super -SBM efficiency on different levels of $\alpha$. } \\
\cline { 2 - 13 } & $\alpha=0$ & $\alpha=0.1$ & $\alpha=0.2$ & $\alpha=0.3$ & $\alpha=0.4$ & $\alpha=0.5$ & $\alpha=0.6$ & $\alpha=0.7$ & $\alpha=0.8$ & $\alpha=0.9$ & $\alpha=0.1$ \\
\hline DMU4 & 3.535 & 3.529 & 3.524 & 3.518 & 3.513 & 3.508 & 3.502 & 3.497 & 3.492 & 3.486 & 3.481 \\
DMU5 & 1.227 & 1.226 & 1.225 & 1.224 & 1.223 & 1.222 & 1.221 & 1.220 & 1.219 & 1.218 & 1.217 \\
DMU8 & 1.399 & 1.388 & 1.378 & 1.368 & 1.357 & 1.346 & 1.335 & 1.324 & 1.319 & 1.316 & 1.313 \\
DMU9 & 1.131 & 1.128 & 1.125 & 1.122 & 1.119 & 1.116 & 1.113 & 1.109 & 1.106 & 1.103 & 1.100 \\
DMU10 & 1.079 & 1.078 & 1.078 & 1.077 & 1.076 & 1.075 & 1.075 & 1.074 & 1.073 & 1.073 & 1.072 \\
DMU16 & 1.060 & 1.059 & 1.058 & 1.057 & 1.056 & 1.055 & 1.053 & 1.053 & 1.052 & 1.051 & 1.050 \\
DMU17 & 1.066 & 1.065 & 1.064 & 1.063 & 1.061 & 1.060 & 1.059 & 1.058 & 1.056 & 1.055 & 1.054 \\
DMU19 & 1.132 & 1.131 & 1.129 & 1.128 & 1.126 & 1.125 & 1.124 & 1.122 & 1.121 & 1.119 & 1.118 \\
DMU20 & 1.099 & 1.098 & 1.097 & 1.095 & 1.094 & 1.093 & 1.091 & 1.090 & 1.088 & 1.087 & 1.086 \\
DMU21 & 1.116 & 1.114 & 1.112 & 1.110 & 1.107 & 1.105 & 1.103 & 1.101 & 1.099 & 1.097 & 1.095
\end{tabular}




\begin{tabular}{|c|c|c|c|c|}
\hline DMU24 & 1.123 & 11 & 1121 & \\
\hline
\end{tabular}

The results of fuzzy BCC model and fuzzy SMB model are having the same shortcoming and we cannot rank the DMUs, because in both the models the efficiency is denoted as 1. Therefore, I order to overcome from this weakness, we are using fuzzy supper efficiency model based on the slacks. Fuzzy supper SBM excludes all inefficient DMUs and rank all those efficient DMUs, whose efficiency score is equal to unity in the fuzzy SBM model. Such that all those DMUs will be rank easily. In Table 6, we are showing the supper efficiency lower bounds of efficient DMUs at different levels of $\alpha$ and supper efficiency upper bounds at same levels $\alpha$ are present in the Table8.

Table 8: Ranking as per Fuzzy Efficiency Scores

\begin{tabular}{|c|c|c|c|c|c|c|c|c|c|c|c|c|c|}
\hline Fuzzy & $\begin{array}{l}\mathbf{D M} \\
\mathbf{U}\end{array}$ & 1 & 2 & 3 & 4 & 5 & 6 & 7 & 8 & 9 & 10 & 11 & 12 \\
\hline \multirow{3}{*}{$\mathrm{BCC}$} & \multirow{2}{*}{ EFF } & 0.84 & 0.90 & 0.77 & 1.00 & 1.00 & 1.00 & 0.68 & 1.00 & 1.00 & 1.00 & 0.90 & 1.00 \\
\hline & & 2 & 8 & 7 & 0 & 0 & 0 & 4 & 0 & 0 & 0 & 4 & 0 \\
\hline & $\begin{array}{l}\text { Ran } \\
\mathrm{k}\end{array}$ & 17 & 15 & 19 & 1 & 1 & 1 & 22 & 1 & 1 & 1 & 16 & 1 \\
\hline \multirow{3}{*}{ SBM } & EFF & 0.58 & 0.89 & 0.76 & 1.00 & 1.00 & 1.00 & 0.15 & 1.00 & 1.00 & 1.00 & 0.49 & 1.00 \\
\hline & EFT & 5 & 2 & 0 & 0 & 0 & 0 & 4 & 0 & 0 & 0 & 6 & 0 \\
\hline & $\begin{array}{l}\text { Ran } \\
\mathrm{k}\end{array}$ & 17 & 14 & 15 & 1 & 1 & 13 & 23 & 1 & 1 & 1 & 18 & 12 \\
\hline \multirow{3}{*}{$\begin{array}{l}\text { Sup. } \\
\text { SBM }\end{array}$} & \multirow{2}{*}{ EFF } & 0.16 & 0.27 & 0.22 & 0.98 & 0.33 & 0.27 & 0.04 & 0.37 & 0.31 & 0.30 & 0.14 & 0.27 \\
\hline & & 8 & 4 & 5 & 3 & 8 & 9 & 5 & 4 & 0 & 0 & 4 & 9 \\
\hline & $\begin{array}{l}\text { Ran } \\
\mathrm{k}\end{array}$ & 17 & 14 & 16 & 1 & 3 & 13 & 23 & 2 & 6 & 9 & 18 & 12 \\
\hline Fuzzy & $\begin{array}{l}\text { DM } \\
\text { U }\end{array}$ & 13 & 14 & 15 & 16 & 17 & 18 & 19 & 20 & 21 & 22 & 23 & 24 \\
\hline \multirow{3}{*}{$\mathrm{BCC}$} & \multirow{2}{*}{ EFF } & 0.08 & 0.57 & 0.79 & 1.00 & 1.00 & 0.74 & 1.00 & 1.00 & 1.00 & 0.75 & 0.94 & 1.00 \\
\hline & & 1 & 4 & 0 & 0 & 0 & 2 & 0 & 0 & 0 & 7 & 4 & 0 \\
\hline & $\begin{array}{l}\text { Ran } \\
\mathrm{k}\end{array}$ & 24 & 23 & 18 & 1 & 1 & 21 & 1 & 1 & 1 & 20 & 14 & 1 \\
\hline \multirow{3}{*}{ SBM } & \multirow{2}{*}{ EFF } & 0.04 & 0.44 & 0.74 & 1.00 & 1.00 & 0.43 & 1.00 & 1.00 & 1.00 & 0.31 & 0.38 & 1.00 \\
\hline & & 0 & 4 & 5 & 0 & 0 & 3 & 0 & 0 & 0 & 4 & 3 & 0 \\
\hline & $\begin{array}{l}\text { Ran } \\
\mathrm{k}\end{array}$ & 24 & 19 & 16 & 1 & 1 & 20 & 1 & 1 & 1 & 22 & 21 & 1 \\
\hline \multirow{3}{*}{$\begin{array}{l}\text { Sup. } \\
\text { SBM }\end{array}$} & \multirow{2}{*}{ EFF } & 0.01 & 0.13 & 0.23 & 0.29 & 0.29 & 0.12 & 0.31 & 0.30 & 0.30 & 0.08 & 0.11 & 0.31 \\
\hline & & 1 & 0 & 6 & 4 & 5 & 5 & 3 & 4 & 7 & 9 & 4 & 2 \\
\hline & $\begin{array}{l}\text { Ran } \\
\mathrm{k}\end{array}$ & 24 & 19 & 15 & 11 & 10 & 20 & 4 & 8 & 7 & 22 & 21 & 5 \\
\hline
\end{tabular}

The ranking through fuzzy BCC and fuzzy SBM models are not genuine ranking which is acceptable for all. While as the ranking by making the use of fuzzy supper SBM model is genuine and generally acceptable to all. From the above analysis, it was observed that DMU 4 is top-ranked DMU (Bank) on the other said DMU13 is bottom ranked DMU.

\section{Conclusions}

DEA has wide application to evaluate the relative efficiency in the set of DMUs by using multiple inputs to produce multiple outputs. Evaluating performance in many activities by a traditional DEA approach requires precise input-output data. However in the real world, it is not always possible, in many empirical studies inputs and outputs are volatile, 
hybrid and complex to deal such type of inputs and outputs fuzzy set theory has been proposed a way quantify imprecise and vague data in DEA models.

In this paper, three kinds of fuzzy DEA models are proposed for evaluating the relative efficiencies of DMUs having fuzzy data and it was concluded that the proposed fuzzy DEA models are more powerful and general approach forms where uncertainty, interval, high frequency and hybrid data can be handled easily.

\section{References}

1. Abbasbandy, S., Ezzati, R., \& Jafarian, A. (2006). LU decomposition method for solving a fuzzy system of linear equations. Applied Mathematics and Computation, 172(1), 633-643.

2. Carlsson, C., \& Korhonen, P. (1986). A parametric approach to fuzzy linear programming. Fuzzy sets and systems, 20(1), 17-30.

3. Chen, C. B., \& Klein, C. M. (1997). An efficient approach to solving fuzzy MADM problems. Fuzzy Sets and Systems, 88(1), 51-67.

4. Chen, Y. C., Chiu, Y. H., Huang, C. W., \& Tu, C. H. (2013). The analysis of bank business performance and market risk-Applying Fuzzy DEA. Economic Modelling, 32, 225-232.

5. Dar, Q. F., Padi, T. R., \& Tali, A. M. (2016). Mixed input and output orientations of Data Envelopment Analysis with Linear Fractional Programming and Least Distance Measures. Statistics, Optimization \& Information Computing, 4(4), 326341.

6. Dar, Q. F., Padi, T. R., \& Tali, A. M. (2017). Decision Support System through Data Envelopment Analysis \& Stochastic Frontier Analysis. Int. J. Modern Math. Sci, 15(1), 1-13.

7. Emrouznejad, A., Tavana, M., \& Hatami-Marbini, A. (2014). The state of the art in fuzzy data envelopment analysis. Performance measurement with fuzzy data envelopment analysis(pp. 1-45). Springer Berlin Heidelberg.

8. Girod, O. A. (1996). Measuring technical efficiency in a fuzzy environment (Doctoral dissertation, Virginia Polytechnic Institute and State University).

9. Guo, P., \& Tanaka, H. (2001). Fuzzy DEA: a perceptual evaluation method. Fuzzy sets and systems, 119(1), 149-160.

10. Hsiao, B., Chern, C. C., Chiu, Y. H., \& Chiu, C. R. (2011). Using fuzzy superefficiency slack-based measure data envelopment analysis to evaluate Taiwan's commercial bank efficiency. Expert Systems with Applications, 38(8), 9147-9156.

11. Jahanshahloo, G. R., Lotfi, F. H., \& Izadikhah, M. (2006). Extension of the TOPSIS method for decision-making problems with fuzzy data. Applied Mathematics and Computation, 181(2), 1544-1551.

12. Kahraman, C., \& Tolga, E. (1998, May). Data envelopment analysis using fuzzy concept. In Multiple-Valued Logic, 1998. Proceedings. 1998 28th IEEE International Symposium on (pp. 338-343). IEEE.

13. León, T., Liern, V., Ruiz, J. L., \& Sirvent, I. (2003). A fuzzy mathematical programming approach to the assessment of efficiency with DEA models. Fuzzy sets and systems, 139(2), 407-419. 
14. Lertworasirikul, S., Fang, S. C., Joines, J. A., \& Nuttle, H. L. (2003). Fuzzy data envelopment analysis (DEA): a possibility approach. Fuzzy sets and Systems, 139(2), 379-394.

15. Liu, S. T. (2008). A fuzzy DEA/AR approach to the selection of flexible manufacturing systems. Computers \& Industrial Engineering, 54(1), 66-76.

16. Puri, J., \& Yadav, S. P. (2013). A concept of fuzzy input mix-efficiency in fuzzy DEA and its application in banking sector. Expert Systems with Applications, 40(5), 1437-1450.

17. Saati, S. M., Memariani, A., \& Jahanshahloo, G. R. (2002). Efficiency analysis and ranking of DMUs with fuzzy data. Fuzzy Optimization and Decision Making, 1(3), 255-267.

18. Sengupta, J. K. (1992). A fuzzy systems approach in data envelopment analysis. Computers \& Mathematics with Applications, 24(8-9), 259-266.

19. Tali, A. M., Padi, T. R., \& Dar, Q. F. (2017). Slack-based Measures of Efficiency in Two-stage Process: An Approach Based on Data Envelopment Analysis with Double Frontiers. International Journal of Latest Trends in Finance and Economic Sciences, 6(3), 1194-1204.

20. Wanke, P., Barros, C. P., \& Emrouznejad, A. (2016). Assessing productive efficiency of banks using integrated Fuzzy-DEA and bootstrapping: A case of Mozambican banks. European Journal of Operational Research, 249(1), 378-389.

21. Yager, R. R. (1981). A procedure for ordering fuzzy subsets of the unit interval. Information sciences, 24(2), 143-161.

22. Zadeh, L. A. (1965). Fuzzy sets. Information and control, 8(3), 338-353.

23. Zadeh, Lotfi A. "Fuzzy sets as a basis for a theory of possibility." Fuzzy sets and systems 100 (1999): 9-34.

24. Zimmermann, H. J. (1978). Fuzzy programming and linear programming with several objective functions. Fuzzy sets and systems, 1(1), 45-55. 